\title{
Role of Heat Shock Protein Derived from Streptococcus sanguinis in Behcet's Disease
}

\author{
Fumio Kaneko ${ }^{1 *}$, Ari Togashi ${ }^{1}$, Erika Nomura ${ }^{1}$, Koichiro Nakamura ${ }^{2}$, Emiko Isogai ${ }^{3}, K_{\text {Kenji Yokota }}^{4}$ and Keiji Oguma $^{4}$ \\ ${ }^{1}$ Institute of Dermato-Immunology and Allergy, Southern Tohoku Research Institute for Neuroscience, Koriyama, Japan \\ ${ }^{2}$ Department of Dermatology, Saitama Medical University, Saitama, Japan \\ ${ }^{3}$ Laboratory Microbiology, Graduate School of Agricultural Science, Tohoku University, Sendai, Japan \\ ${ }^{4}$ Department of Bacteriology, Okayama University Graduate School of Medicine and Dentistry, Medical School, Okayama, Japan
}

\begin{abstract}
Patients with Behcet's disease (BD) have hypersensitivity against oral streptococci increased in their oral cavity. Heat shock protein-65/60 (Hsp-65/60) derived from S. sanguinis and the damaged mammalian tissues, respectively, are supposed to play an important role in BD pathogenesis. The antigen presenting cells taken Hsp-65 via Toll-like receptors in the oral lesion are carried to the local lesions by blood flow and they are known to lead T cells undergo apoptosis in the regional delayed type hypersensitive reaction. The human Hsp-60 peptide (336-351 aa) combined with recombinant cholera toxin B subunit was reported to be a therapeutic agent for BD patients with advanced uveitis.

Here, we recognized that the peptide (249-264 aa; designated LO1 and 311-326aa: UK) of Hsp-65/60 exhibiting highly homologous to the T cell-epitope lead CD4+ and CD8+ T cell apoptosis in peripheral blood mononuclear cells from BD patients. In BD patients IL-8 and IL-12 production from activated T cells was significantly inhibited by LO1 and UK peptides. The results suggest that the peptides of $\mathrm{Hsp}-65 / 60$ are able to be therapeutic agents for active BD patients.
\end{abstract}

Keywords: Apoptosis; Behcet's disease; Heat Shock Protein; Streptococcus sanguinis

\section{Introduction}

Behcet's disease (BD) is a chronic inflammatory disorder characterized by starting with oral ulceration and develops the recurrent involvement of muco-cutaneous, ocular, vascular, digestive and/or nervous system organs. $\mathrm{BD}$ symptoms are considered to be based on the correlation between the genetic intrinsic factor and the triggering extrinsic factors, because more than $60 \%$ of $\mathrm{BD}$ patients are associated with HLA-B51 [1,2]. As one of the triggering extrinsic factors, the oral unhygienic condition may be suspected, because periodontitis, decayed teeth, chronic tonsillitis, etc. are frequently noted in the oral cavity of BD patients $[3,4]$. The proportion of Streptococcus sanguinis (S. sanguinis), S. mitis and $S$. mutans was pointed to significantly increase in the oral bacteria flora of BD patients [5-8]. S. sanguinis was previously recognized as species of the genus Streptococcus named "S. sanguis" and the strain isolated from BD patients was different from reference ATCC strains in DNA homology and sugar constituents, which indicate uncommon serotype KTH-1 (so-called BD113-20 strain) [6-8]. Most of the patients tend to acquire delayed type hypersensitivity (DTH) against oral streptococci [3,4,9-11]. The serum-antibody titers against streptococci were also elevated in $\mathrm{BD}$ patients [12]. Our previous trials of the prick reaction by self-saliva revealed that $\mathrm{BD}$ patients can respond to their own saliva including oral streptococci. The phenomena can be used for diagnosis of $\mathrm{BD}$ and recurrent aphthosis and may explain the correlation between oral ulcerations and the systemic involvement in $\mathrm{BD}[13-15,18]$.

The $65 \mathrm{kD}$ aheat shock protein (Hsp-65) related to S. sanguinis can be detected along with a counterpart human Hsp-60 which might reactively appear in the sera and skin lesions of BD patients [15-18]. The lesions are histologically considered to be DTH reaction with perivascular mononuclear cell infiltration [10,19,20]. Generally interleukin (IL)-12 and IL-23 produced by the infiltrated mononuclear cells, which might be antigen presenting cells (APCs), is thought to induce naive $\mathrm{T}(\mathrm{Th} 0)$ cells to $\mathrm{T}$-helper type-1 (Th-1) cells in correlation with DTH reaction [21].

It is of interest that the synthetic peptide of Hsp-60 (336-351 aa) fused with recombinant cholera toxin $\mathrm{B}$ subunit ( $\mathrm{rCTB}$ ) reduced the experimental uveitis induced by the whole Hsp-60 in Lewis strain rats, although the adjuvant-free peptide is also capable of inducing uveitis $[22,23]$. A therapeutic trial with the selective peptides conjugated with rCTB was done by oral administration for BD patients with severe uveitis. In those patients whose disease is inactive, a lack of the peptidereactive $\mathrm{CD} 4+\mathrm{T}$ cell population and reduction of cytokine production from $\mathrm{T}$ cells were found. The Hsps might thus trigger both innate and adaptive immune mechanisms in $\mathrm{BD}$, but on the other hand, the therapeutic approaches involving Hsp immunomodulation may be available as "oral toleration" for $\mathrm{BD}$ patients with advanced uveitis using the restricted peptide of Hsp (336-351) [24]. The four distinct peptides encoding Hsp-65, which have homology to Hsp-60 and T cell epitope, were shown to significantly stimulate and undergo CD4+ and CD8+ T cell apoptosis in peripheral blood mononuclear cells (PBMCs)

*Corresponding author: Fumio kaneko, Institute of Dermato-Immunology and Allergy, Southern Tohoku Research Institute for Neuroscience, Koriyama, Japan, E-mail: f.kaneko@mt.strins.or.jp

Received November 09, 2011; Accepted January 06, 2012; Published January 11,2012

Citation: Kaneko F, Togashi A, Nomura E, Nakamura K, Isogai E, et al. (2012) Role of Heat Shock Protein Derived from Streptococcus sanguinis in Behcet's Disease. J Medical Microbiol Diagnosis S2:001. doi:10.4172/2161-0703.S2-001

Copyright: @ 2012 Kaneko F, et al. This is an open-access article distributed under the terms of the Creative Commons Attribution License, which permits unrestricted use, distribution, and reproduction in any medium, provided the original author and source are credited. 
Citation: Kaneko F, Togashi A, Nomura E, Nakamura K, Isogai E, et al. (2012) Role of Heat Shock Protein Derived from Streptococcus sanguinis in Behcet's Disease. J Medical Microbiol Diagnosis S2:001. doi:10.4172/2161-0703.S2-001

from $\mathrm{BD}$ patients $[17,25]$. Then, we studied to confirm the mechanism of the peptides of Hsp-65/60 to the PBMCs of BD patients.

\section{Methods and Results}

We analyzed Hsp-65 derived from S. sanguinis to find the correlation with the homologous peptides to Hsp-60 and T cell epitope of $\mathrm{BD}$ patients (Figure 1) and prepared the 6 synthetic peptides for incubation with PBMCs from BD patients and healthy individuals (HIs) to find how the peptides behave the cytokine production form PBMCs of BD patients in active disease stage. The patients were 2 females aged 26 and 36 years and 5 males aged from 23 to 55 years (average 39.1 years old) who were mainly suffered from mucocutaneous symptoms including oral aphthous ulceration, erythema nodosum-like eruption, etc. since more than 5 years. All of them were treated with oral streroid ointment and occasional administration of minocycline and non-steroidal anti-

\section{Newly prepared six peptides of Hsp-65(BD 113-20 strain)}

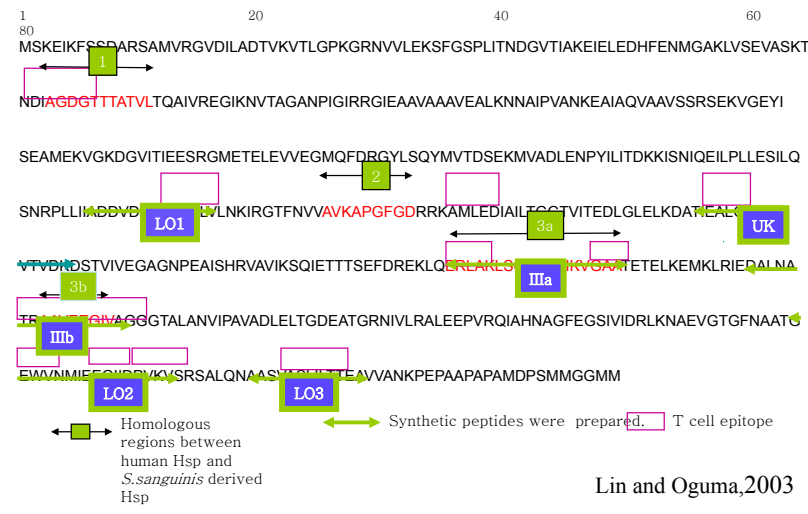

Figure 1: Newly synthesized peptides of Hsp-65 derived from Streptococcus. sanguinis (S. sanguinis) (KTH-1, BD113-20 strain). There are 10 homologous peptides with T cell epitope including LO1, UK, 3a(Illa), 3b(IIllb), LO2 and LO3 which are also highly homologous with human Hsp-60 peptides. UK(311-326aa) is corresponding to the peptide of human Hsp-60(336-351aa).

Synthetic peptides of Hsp-65 derived from S. sanguinis

\begin{tabular}{|c|c|c|c|c|c|}
\hline & & location & umbe & AA sequence & M.W. \\
\hline 1 & LO1 & $249-264$ & 16 & ADDVDGEALPTLVLNK & 1668 \\
\hline 2 & UK & $311-326$ & 16 & TIEALGOAARVTVDKD & 1685 \\
\hline 3 & Illa & $365-384$ & 20 & ERLAKLSGGVAVIIVVGAATE & 1967 \\
\hline 4 & IIIlb & $395-413$ & 19 & EDALNATRAAVEEGIVAGG & 1841 \\
\hline 5 & LO2 & $480-499$ & 20 & GEW/NMIIEGIDPVIVSRS & 2256 \\
\hline 6 & LO3 & $504-518$ & 15 & AASV $\sqrt{\text { ASLILTTTEAW }}$ & 1443 \\
\hline
\end{tabular}

Homologous regions with human Hsp60 $\square$ T cell epitope Lin and Oguma,2003

Picture 1: Synthetic peptides of Hsp-65 derived from S. sanguinis. MW: molecular weight (daltons) (Oguma et al., 2008). The peptides are highly homologous to human Hsp-60 (red alphabets) and also homologous with T cell epitope.
LO1, LO2, LO3, III-b and UK peptide showed different IL-12 responses between BD patients and healthy individuals (HIs)

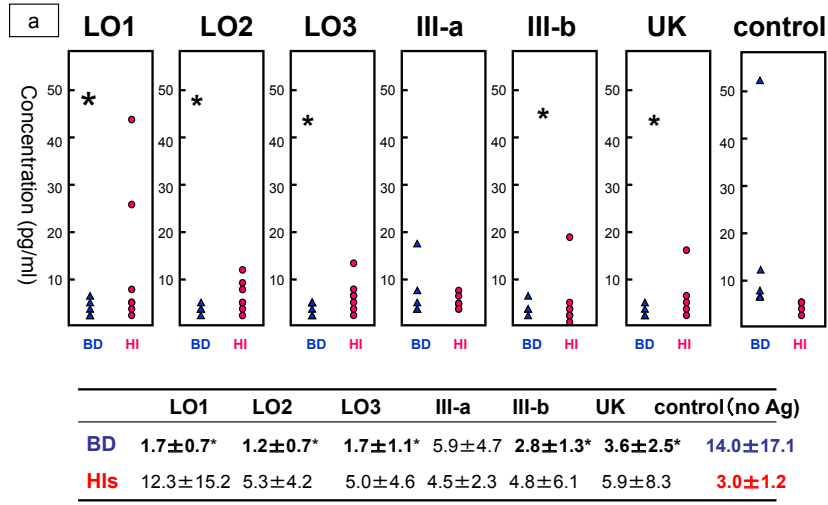

b The L01,III-a and III-b peptides showed different IL-8 responses between BD patients and HIs

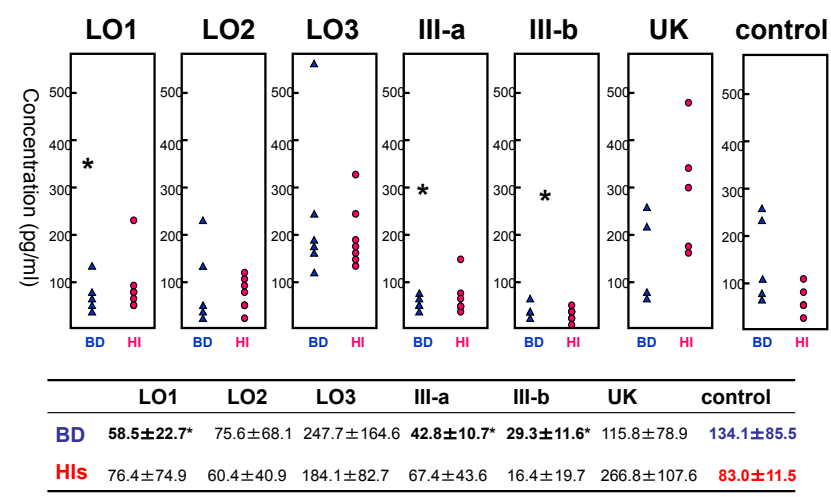

Figure 2: Effects of the peptides of Hsp-65 to proinflammatory cytokine production. a. IL-12 was highly produced by PBMCs from active BD patients without stimulation (Control). IL-12 production from BD patients was significantly reduced by incubation with LO1, LO2, LO3, III-b and UK $\left(^{*}\right)$. On the other hand, IL-12 production from PBMCs of HIs was all elevated by these peptides (red points). b. LO1, III-a and III-b significantly reduced IL-8 production from PBMCs of BD patients $\left.{ }^{*}\right)$ in comparison with the control level of cytokine production. On the other hand, IL-8 production was accelerated from PBMCs of HIs by these peptides.

inflammatory drugs. HIs were 3 females aged from 28 to 31 (average 30.7 years old) and 4 males aged from 29 to 38 years (average 32.3 years old).

The peptides, LO1 (249-264), IIIa (365-384), IIIb (395-413), LO2 (480-499), LO3 (504-518) and UK (311-326) corresponding to the human Hsp-60 (336-351) were prepared to contain $25 \mu \mathrm{g} / \mathrm{ml}$ in phosphate buffered saline (PBS) (Picture 1). PBMCs $\left(10^{6} \mathrm{cells} / \mathrm{ml}\right.$ in PBS) from 7 active BD patients and 5 HIs were incubated with and without these peptides. The 7 day-culture supernatants were measured mainly for IL-8 and IL-12 production by antigen-specific ELISA and compared with those from PBMCs of active BD patients incubated without the peptides as controls. Although these cytokines were naturally produced from PBMCs of active BD patients, the significant reduction of inflammatory cytokines was found by incubating with the 5 peptides, LO1, LO2, LO3, IIIb and UK (Figure 2a,b).

In order to learn the suppressive mechanisms of the proinflammatory cytokine production in PBMCs from active BD patients by the peptides of Hsp-65/60, we took LO1, LO2 and UK to 
find the reduction mechanism of IL-8 and IL-12. Using NOMO-1 cells (human macrophage cell line) and U937 (J-Global, Japan) stimulated by $S$. sanguinis antigen $(5 \mu \mathrm{g} / \mathrm{ml})$ (BD 113-20 Ag) which produce IL-8, an attempt to add the peptites the cell incubation was done. The results showed that IL-8 production of the antigen-stimulated NOMO-1 cells were suppressed by incubation with LO1 and UK in a dose dependent manner, though the LO2 peptide failed to reduce the production (Figure 3). Also, we analyzed the stimulated NOMO-1 cells treated with or without the peptides to find cytokine gene expression using by GeneChip (Gene Chip; Human Genome, U133 Plas2.0 Array) and various expression of cytokine genes were observed (Picture 2). It is of interest that mRNA of CD58 (lymphocyte function-associated antigen-3; LFA-3) and FK506 (Taculolimus) binding protein (bp) was intensely increased on the cell membrane of the antigen-stimulated NOMO-1 when they were treated with LO1 and UK. It might be considered that antigen-activated $\mathrm{T}$ cells of $\mathrm{BD}$ patients underwent apoptosis by binding of LO1 and UK peptides on the cell surface receptor.

\section{Discussion}

Although the etiology of $\mathrm{BD}$ is still obscure, the clinical manifestations generally start with oral aphthous ulceration and develop systemic involvement. The close correlation between the genetic internal and triggering external factors is thought to be present in the $\mathrm{BD}$ pathogenesis. Most of $\mathrm{BD}$ patients tend to acquire hypersensitivity against streptococci in the oral cavity and express DTH reaction mediated by IL-12 and/or IL-23 in the various lesions $[20,26]$. Hsp-65/60, which is derived from oral screptococci and human damaged tissue, seems to play an important role in $\mathrm{BD}$ pathogenesis. The peptides of Hsp-65/60, which are homologous with T cell epitope, reduce the function of PBMCs from $\mathrm{BD}$ patients with active stage, though the Hsps stimulate the immune cells of HIs. It might be explained that when the APCs taken streptococcal agents via Toll-like receptors (TLRs) in the oral cavity were locally curried and adhered to the damaged vessel walls, the DTH response developed to the

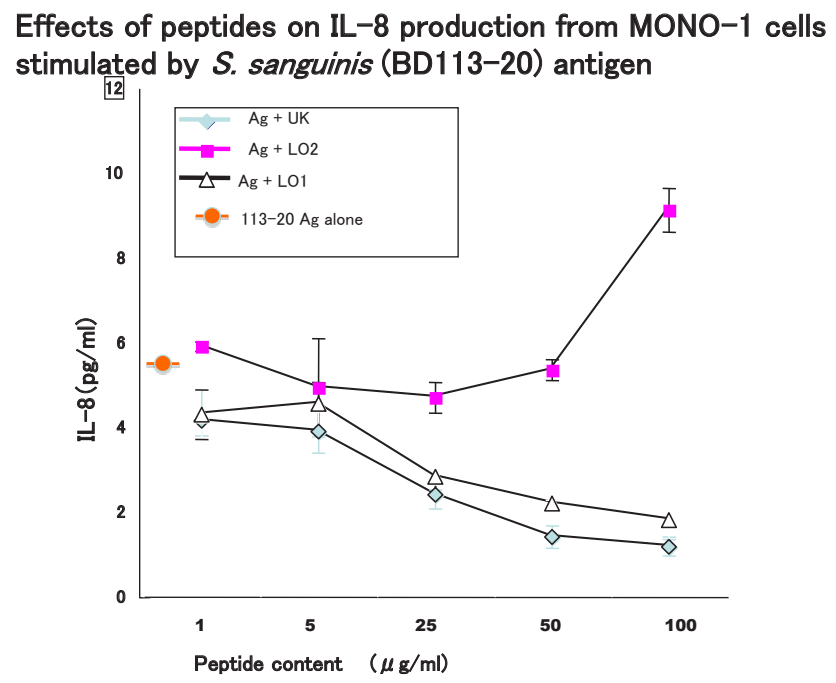

Figure 3: IL-8 production from NOMO-1 cells (human macrophage cell line) activated by $S$. sanguinis antigen was suppressed by LO1 and UK in a dose dependent manner. On the other hand, LO2 showed no suppression of IL-8 production.

\begin{tabular}{|c|c|c|c|}
\hline \multicolumn{4}{|c|}{$\begin{array}{l}\text { GeneChip }{ }^{\circledR} \text { Human Genome; check the expression of } 47,000 \text { genes } \\
\text { NOMO-1 cells were treated with S. sanguinis (BD113-20) cell lysate, } \\
\text { and mRNA were assayed. Then, the expression of cytokine mRNA } \\
\text { and expressions CD58 and FF506 receptors was checked. }\end{array}$} \\
\hline $113-20 \mathrm{Ag}(5 \mu \mathrm{g} / \mathrm{ml})$ & & Treated & Treated \\
\hline Peptide $(25 \mu \mathrm{g} / \mathrm{ml})$ & - & Incubated without & Incubated with \\
\hline Increased cytokines & & $\begin{array}{l}\text { IL-12B p40, } \\
\text { TNFAIP6、TRAF 1, } \\
\text { CCL-4、IL-10, } \\
\text { IL-1 }, \text { CCL-20, } \\
\text { IL-1a、IL-7R, } \\
\text { CXCL-2 }\end{array}$ & $\begin{array}{l}\text { IL-12B } \\
\text { IL-23A } \\
\text { IL-1a }\end{array}$ \\
\hline $\begin{array}{l}\text { Decreased } \\
\text { cytokines }\end{array}$ & & $\begin{array}{l}\text { IL-13 Ra1 } \\
\text { IL-17 R, IL-16 }\end{array}$ & $\begin{array}{l}\text { IFN-lambda (IL-28) } \\
\text { IL-10, }\end{array}$ \\
\hline $\begin{array}{l}\text { Increased receptor } \\
\text { etc. }\end{array}$ & & & \begin{tabular}{|l}
-CD58(CD2 ligand) \\
-FK506 binding protein
\end{tabular} \\
\hline
\end{tabular}

Picture 2: Expression of cytokine mRNAs on NOMO1 cells (human macrophage cell line) treated with or without $S$. sanguinis (BD113-20) antigen. The production of inflammatory cytokines fom NOMO-1 cells was influenced by the antigen treatment. FK506 (taculolimus) binding protein (bp) and CD58 (lymphocyte function-associated antigen-3) receptors were clearly expressed on the cell membrane.

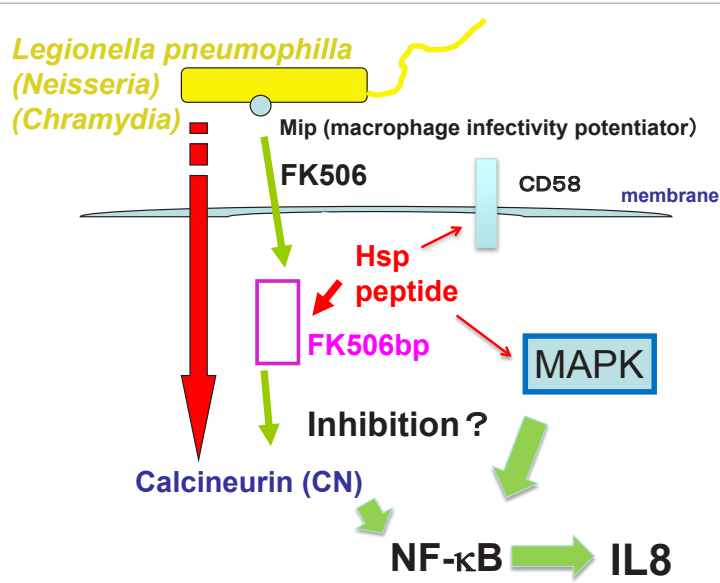

Yokota and Oguma, 2010

Figure 4: Expression of FK506 binding protein (bp) and CD58 (lymphocyte function-associated antigen $3:$ LFA-3) receptors on the cell membrane of NOMO1 cell after application of $S$. sanguinis (BD113-20) antigen. FK506 bp, which combines immunosuppresive agent of FK506 (Tacrolimus), is composed of more than 20 proteins. It is known that some bacteria such as Legionella pneumophilla etc. via FK506bp of the cell membrane reduce the cytokine production from the macrophages after binding to calcineurin $(\mathrm{CN})$ affecting the nuclear factor (NF$\mathrm{KB}$ ) of activated macrophage. (MAPK: mitogen-activated protein kinase).

various clinical symptoms of BD patients , as previously shown $[15,18]$ Regarding TLRs to bacteria and their products in the innate immunity, TLR 2, 4, 6 and 9 are known to be expressed $[28,29]$ and it has been already reported that these TLRs are expressed at the reactive immune infiltrates in $\mathrm{BD}$ patients [30].

The probability of a new therapy for BD patients was described as the immune tolerance utilizing the peptides of Hsp-65/60. In order to know the effects of Hsp-65/60-peptides, the five peptides were applied on $\mathrm{BD}$ patients' $\mathrm{PBMCs}$ activated, respectively. The results indicated 
Citation: Kaneko F, Togashi A, Nomura E, Nakamura K, Isogai E, et al. (2012) Role of Heat Shock Protein Derived from Streptococcus sanguinis in Behcet's Disease. J Medical Microbiol Diagnosis S2:001. doi:10.4172/2161-0703.S2-001

that LO1 and UK peptides significantly reduced the production of IL- 8 and IL-12 from activated PBMCs of BD patients. Also, to understand the reduction mechanism of cytokines from the PBMCs, the effects of LO1, LO2 and UK on NOMO-1 cells stimulated with S. sanguinis antigen were analyzed by a cDNA-microarray procedure. In the NOMO1 cells, mRNA expression of IL-16, IL-10 and IL-28-receptors was reduced though IL-12p40, IL23A and IL-1 $\alpha$ were up-regulated. CD58 receptor and FK506 binding protein were enhanced by LO1 peptide, indicating the HSP65/60-peptides influence the cytokine production from NOMO-1 cells. The peptides may work to express FK506 bp and CD58 on the cell membrane of lymphoid cells from active BD patients as indicated that the behave of NOMO-cells might be considered as shown in (Figure 4). We tried to find the binding sites of the peptides on monocytes by cDNA microarray chips. The paneled cDNAs were obtained from NOMO-1 cells stimulated by S. sanguinis (BD113-20) antigen. From the results we speculated that CD58 molecule and/or FK506 binding protein were highly expressed on the cell surface of the NOMO-1 cells by the LO1 stimulation (Figure 4 and Picture 2) [27]. These results may indicate a new therapeutic strategy for BD patients as demonstrated before [31].

\section{Conclusions}

As one of the triggering external factors, streptococci including $S$. sanguinis increased in the oral cavity play an important role in $\mathrm{BD}$ patients. Especially, Hsp-65/60 derived from oral streptococci seems to cause various lesions of $\mathrm{BD}$ patients, but on the other hand, some peptides composed of the Hsp, which are homologous with T-cell epitope, are able to reduce proinflammatory cytokine production from immune reactive cells of active $\mathrm{BD}$ patients. These kind of the peptides may also be therapeutic agents for active $\mathrm{BD}$ patients, as previously reported [24].

\section{Acknowledgments}

We deeply appreciate the financial support from the Study Group of Behcet's Disease (Director: Professor Yoshiaki Ishigatsubo, Department of Rheumatology, Yokohama City University School of Medicine) organized by the Japanese Ministry of Health, Labour and Welfare.

\section{References}

1. Kalayciyan A, Zouboulis C (2007) An update on Behcet's disease. J Eur Acad Dermatol Venereol 21: 1-10.

2. Ohno S, Ohguchi M, Hirose S, Matsuda H, Wakisaka A, et al. (1982) Close association of HLA-Bw51 with Behcet's disease. Arch Ophthalmol 100: 14551458.

3. Kaneko F, Kaneda T, Ohnishi O, Kishiyama K. Takashima I, et al. (1978) Infection allergy in Behcet's disease. Jpn J Allergol 27: 440-450.

4. Kaneko F, Oyama N, Nishibu A (1997) Streptococcal infection in the pathogenesis of Behcet's disese and clinical effects of minocycline on the disease symptoms. Yonsei Med J 38: 444-454

5. Mumcu G, Inanc N, Aydin SZ, Ergun T, Direskeneli H (2009) Association of salivary $S$. mutans colonization and mannose-binding lectin deficiency with gender in Behcet's disease. Clin Exp Reumatol 27: S32-S36.

6. Yokota K, Hayashi S, Araki Y, Isogai E, Kotake S, et al. (1995) Characterization of Streptococcus sanguis isolated from patients with Behcet's disease. Microbiol Immunol 39: 729-732.

7. Isogai E, Ohno S, Takashi K, Yoshikawa K, Turumizu T, et al. (1990) Close association of Streptococcus sanguis uncommon serotypes with Behcet's disease. Bifidobacteria Microflora 9: 27-41

8. Isogai E, Ohno S, Kotake S, Isogai H, Turumizu T, et al. (1990) Chemiluminescence of neutrophils from patients with Behcet's disease and its correlation with an increased proportion of uncommon serotypes of Streptococcus sanguis in the oral flora. Arch Oral Biol 35: 43-48.

9. Graykowski EA, Barile MF, Lee WB, Stanley HR (1966) Recurrent aphthous stomatitis: Clinical therapeutic, histopathologic and hypersensitivity aspects. JAMA 196: 637-644.

10. Kaneko F, Takahashi Y, Muramatsu Y, Miura Y (1985) Immunological studies on aphthous ulcer and erythema nodosum-like eruptions in Behcet's disease. Br J Dermatol 113: 303-312.

11. (1989) Skin hypersensitivity to streptococcal antigens and the induction of systemic symptoms by the antigens in Behcet's disease-A multicenter study The Behcet's Disease Research Committee of Japan. J Rheumatol 16: 506511

12. Yokota K, Hayashi S, Fujii N, Yoshikawa K, Kotake S, et al. (1992) Antibody response to oral streptococci in Behcet's disease. Microbiol Immunol 36: 815822

13. Kaneko F, Saito S, Togashi A, Oyama N, Nakamura K (2010) Prick test with self-saliva as an auxiliary diagnostic measure in Behcet's disease. Jpn J Dermatol 120: 1901-1905.

14. Togashi A, Saito S, Kaneko F, Nakamura K, Oyama N (2011) Skin prick tes with self-saliva in patients with oral aphthoses: A diagnostic pathergy for Behcet's disease and recurrent aphthosis. Inflam Allergy Drug Targets 10: 164 170.

15. Kaneko F, Togashi A, Saito S, Sakuma H, Oyama N, et al. (2011) Behcet's disease (Adamantiades-Behcet's disease). Clin Dev Immunol 2011: 681956.

16. Lehner T (1997) The role of heat shock protein, microbial and autoimmune agents in the aetiology of Behcet's disease. Int Rev Immunol 14: 21-32.

17. Kaneko S, Suzuki N, Yamashita N, Nakajima T, Wakisaka S, et al. (1997) Characterization of $\mathrm{T}$ cells specific for an epitope of human $60-\mathrm{kD}$ heat shock protein (hsp) in patients with Behcet's disease (BD) in Japan. Clin Exp Immunol 108: $204-212$.

18. Kaneko F, Oyama N, Yanagihori H, Isogai E, Yokota K, et al. (2008) The role of streptococcal hypersentitivity in the pathogenesis of Behcet's disease. Eur J Dermatol 18: 489-498.

19. Kaneko F (1989) Behcet's disease. In: Hiroaki Ueki, Hideo Yaoita, eds. A Colour Atlas of Dermato-Immunohistology. Wolf Medical Publications Ltd. London, 84-86.

20. Lew W, Chang JY, Bang D (2008) Increased expression of interleukin-23p19 mRNA in erythema nodosum-like lesions of Behcet's disease. $\mathrm{Br} \mathrm{J}$ Dermato 158: $505-511$.

21. Trinchieri G (1993) Interleukin-12 and its role in the generation of TH1 cells Immunol Today 14: 335-338.

22. Hu W, Hasan A, Wilson A, Stanford MR, Li-Yang Y, et al. (1998) Experimenta mucosal induction of uveitis with the $60-\mathrm{kDa}$ heat shock protein-derived peptide 336-351. Eur J Immunol 28: 2444-2455

23. Phipps PA, Stanford MR, Sun JB, Xiao BG, Holmgren J, et al. (2003) Prevention of mucosally induced uveitis with a HSP60-derived peptide linked to cholera toxin B subunit. Eur J Immunol 33: 224-232

24. Stanford M, Whittall T, Bergemeier LA, Linbdald M, Lundin S, et al. (2004) Ora tolerization with peptide 336-351 linked to cholera toxin B subunit in preventing relapses of uveitis in Behcet's disease. Clin Exp Immunol 137: 201-208.

25. Pervin K, Chlderstone A, Shinnick T, Mizushima $\mathrm{Y}$, van der Zee R, et al. (1993) $T$ cell epitope expression of mycobacterial and homologous human 65-kilodalton heat shock protein peptides in short term cell lines from patients with Behcet's disease. J Immunol 151: 2273-2282.

26. Yanagihori H, Oyama N, Nakamura K, Mizuki K, Kaneko F (2006) Role of IL 12B promoter polymorphism in Adamantiades-Behcet's disease susceptibility: An involvement of Th1 immunoreactivity against Streptococcus sanguinis antigen. J Invest Dermatol 126: 1534-1540.

27. Oguma K, Shin R, Yokota K (2008) Studies on immunological responses by bacterial antigens in Behcet's disease. Reports of the Research Group for 
Citation: Kaneko F, Togashi A, Nomura E, Nakamura K, Isogai E, et al. (2012) Role of Heat Shock Protein Derived from Streptococcus sanguinis in Behcet's Disease. J Medical Microbiol Diagnosis S2:001. doi:10.4172/2161-0703.S2-001

Behcet's disease organized by the Japanese Ministry of Health, Labour and Welfare, 2006-2007: 31-33. (in Japanese)

28. Zarember KA, Godowski PJ (2002) Tissue expression of human Toll-like receptors and differential regulation of Toll-like receptor mRNAs in leukocytes in response to microbes, their products and cytokines. J Immunol 168: 554-561.

29. Hornung V, Rothenfusser S, Britsch S, Krug A, Jahrsdorfer B, et al. (2002) Quantitative expression of Toll-like receptor 1-10 mRNA in cellular subsets of human peripheral blood mononuclear cells and sensitivity to CpG oligodeoxynucleotides. J Immunol 168: 4531-4537.
30. Yavuz S, Elbir A, Tulunay A, Eksioglu-Demiralp E, Direskeneli H (2008) Differential expression of toll-like receptor 6 on granulocytes and monocytes implicates the role of microorganisms in Behcet's disease etiopathogenesis. Rheumatol Int 28: 401-406.

31. Kaneko F, Togashi A, Oyama N, Nakamura K, Isogai E, et al. (2010) Therapeutic possibility for patients with Behcet's disease by peptides of heat shock protein-65/60 derived from oral streptococci. $14^{\text {th }}$ International Congress on Behcet's Disease in London 34-35. 